\title{
HRV in Active-Duty Special Forces and Public Order Military Personnel
}

\author{
Giuseppe Gancitano $^{1}$, Antonio Baldassarre ${ }^{2, *(\mathbb{D})}$, Luigi Isaia Lecca $\left.{ }^{2}{ }^{(}\right)$, Nicola Mucci ${ }^{2}{ }^{(}$, Marco Petranelli ${ }^{2}$, \\ Mario Nicolia ${ }^{1}$, Antonio Brancazio ${ }^{3}$, Andrea Tessarolo ${ }^{1}$ and Giulio Arcangeli ${ }^{2}$ \\ 1 1st "Tuscania" Paratrooper Regiment Carabinieri, Italian Ministry of Defense, 57127 Livorno, Italy; \\ giuseppe.gancintano@carabinieri.it (G.G.); mario.nicolia@carabinieri.it (M.N.); \\ andrea.tessarolo@carabinieri.it (A.T.) \\ 2 Department of Experimental and Clinical Medicine, University of Florence, 50134 Florence, Italy; \\ luigiisaia.lecca@unifi.it (L.I.L.); nicola.mucci@unifi.it (N.M.); marcopetranelli@gmail.com (M.P.); \\ giulio.arcangeli@unifi.it (G.A.) \\ 3 Warrant Officer and Brigadier Training School, Carabinieri Italian Ministry of Defense, \\ 50127 Florence, Italy; antonio.brancazio@carabinieri.it \\ * Correspondence: antonio.baldassarre@unifi.it
}

Citation: Gancitano, G.; Baldassarre,

A.; Lecca, L.I.; Mucci, N.; Petranelli,

M.; Nicolia, M.; Brancazio, A.;

Tessarolo, A.; Arcangeli, G. HRV in

Active-Duty Special Forces and

Public Order Military Personnel.

Sustainability 2021, 13, 3867. https://

doi.org/10.3390/su13073867

Academic Editor: Santos Villafaina

Received: 29 January 2021

Accepted: 29 March 2021

Published: 31 March 2021

Publisher's Note: MDPI stays neutral with regard to jurisdictional claims in published maps and institutional affiliations.

\begin{abstract}
Heart rate variability (HRV) is a simple, non-invasive, real-time analyzable, and highly reproducible measurement that captures incidences for assessing a person's health and physical condition. Public security jobs are characterized by major exposure to risk factors known to influence the cardiovascular response to stimuli, e.g., night shifts, highly physically demanding activity, and acute stress activity. This study aimed to evaluate the HRV parameters in a population of 112 male personnel of the special forces and public order of the Carabinieri, aged 25-59, when engaged in several duty tasks, such as paratroopers, night shift police station officers, night shift patrol, dynamic precision shooting evaluative team, dynamic precision shooting non-evaluative team, and office clerks (used as control group). During the specific task of each participant, the HRV parameters were collected with wearable devices and processed. The HRV parameters in the time and frequency domains collected were average heart rate, standard deviation of all normal RR intervals, root mean square of successive differences in adjacent normal-to-normal (NN) intervals, very-low-frequency power, low-frequency power, high-frequency power, stress index, parasympathetic nervous system activity index, and sympathetic nervous system activity index. Parametric tests for independent series to compare the HRV parameters by subgroups within the study subjects were used. A multivariate linear regression analysis was conducted to evaluate the association between the HRV parameters and some personal and organizational factors. The comparison between different subgroups showed that activities with a high demand for concentration and precision, as is the case with paratroopers and dynamic precision shooters, differ significantly from activities that can be defined as routine, such as office work. Other activities, such as patrolling or remote management from operations centers, although including critical elements, did not deviate significantly from the control group. The study of HRV parameters is therefore a useful tool for occupational physicians, both for addressing work suitability assessments and for better targeting health promotion campaigns, to be considered as being aimed at monitoring the subject's physiological parameters, and not at the diagnosis of any pathological condition, which should always be carried out by the medical specialist.
\end{abstract}

Keywords: occupational medicine; public health and safety; special forces personnel; heart rate variability (HRV); paratroopers; health biomarker; high fidelity data acquisition; biosensors

\section{Introduction}

Heart rate variability (HRV) is a simple, non-invasive, analyzable in real time, and highly reproducible measure that represents a significant indicator for assessing health and physical condition. HRV, detecting the oscillations in the interval between consecutive 
instant heartbeats or between the peak $R$ of one beat and the next ( $R R$ interval) in the QRS complex, reflects the action that the two main components of the autonomic nervous system, sympathetic and parasympathetic, play on the sinoatrial node, the point of origin of the cardiac impulse, innervating it with numerous fibers coming in part from the thoracic nerves and in part from the vagus nerve (the tenth cranial nerve, also known as pneumogastric nerve), and acting as a modulation factor of the physiological processes of the human body both in both normal and pathological cases [1-3].

Measurement of HRV can be conducted, reliant on research interest and depending on the capabilities of the device used for recording, from half a minute (short-term) up to $24 \mathrm{~h}$, in compliance with the dictates of the guidelines by the European Society of Cardiology (ESC) and by the North American Society of Electrophysiological Stimulation (NASPE) [4]. The measures and indicators used today are numerous (Joyce D., Barrett M. 2018), determined by three types of analysis: two linear, located in the time or frequency domain, and a non-linear one, based on the analysis of fractals (chaos theory), now increasingly used in the field of cardiological diagnosis [5].

HRV analysis consists of a series of measurements influenced by numerous factors such as age, posture, state of fatigue, and occupational factors such as stress, night shift work, and highly demanding psychophysical tasks. Changes in HRV can be examined under various conditions, such as when asleep or awake, during physical exertion or relaxation, and even under a pathological condition as an indication of overall autonomic nervous system efficiency, and is therefore an indicator of general health. To date, a shortage of studies has assessed these changes during real working scenarios, especially in those job tasks known to require high psychophysical performance, as is the case with public security officers. Although many authors have studied HRV, few studies are currently available in the literature on HRV assessment in active-duty military personnel.

Public security activity can determine an occupational exposure to various factors, known to influence autonomic cardiovascular response to a variety of stimuli, such as night shifts, highly physically demanding activity, and acute stress activity (i.e., emergency call management and highly demanding training activity). The 1st "Tuscania" Carabinieri Paratrooper Regiment is one of the flagship units of the Carabinieri. It is part of the Special Crowning Operation Units (COOS TIER 3) of the Italian Special Forces. All of the staff in the department are authorized to skydive. This high-profile department has always carried out the typical, characteristic tasks of parachuting troops throughout its history. It has a staff of barely 500 men of various ranks. Regiment candidates, of all ranks, are previously subjected to psychophysical selection, aimed at ascertaining their aptitude for particular employment, and subsequently admitted to a training course, which lasts approximately nine months and includes the following:

- parachuting course;

- patrol and platoon training;

- individual and collective training in the use of weapons.

All operators of the Special Intervention Group (GIS) must pass through the 1st "Tuscania" Carabinieri Paratrooper Regiment. They are volunteers, with an age not exceeding 30 years and with an excellent disciplinary record. The selective tests to access the GIS are very demanding and also consist of medical visits and psycho-aptitude assessments aimed at ascertaining operational capacity in situations of high physical and psychological stress. The objective pursued by this intensive training is the use of a particularly selected element, deeply motivated and capable of distinguishing itself by technique, lucidity, and balance, especially in coordinated activities for special operations. Apart from special periodical training activity, the personnel are involved in all of the typical tasks of public security, e.g., emergency call response, night patrol activity, and coordination activities from operations centers.

The eighth Goal of the United Nation 2030 agenda on sustainable development calls to promote sustained, inclusive, and sustainable economic growth, full and productive employment, and decent work for all. Following this founding principle, the topic of 
employment, decent work for all, and social protection represents a crucial point to perceive this objective (https://sdgs.un.org/goals/goal8 accessed on 5 March 2021). As a result, innovative studies on how new technologies can provide new insight into the knowledge about the relationship between workplace exposures to stressful conditions and the wellbeing of workers are of special interest for organizations and society [6,7].

The aim of the present study was to assess the HRV parameters in a military special force, during the performance of their specific tasks, exposed to various professional factors.

\section{Materials and Methods}

\subsection{Study Population and Procedures}

One hundred and twelve special force and public order male personnel, aged 25-59, also employed as public security officers, were enrolled in the study in the period between March and December 2019. The workers were engaged in several job tasks, divided into six different subgroups: paratroopers (PT), night shift police station officers (NSS), night shift patrol (NSP), dynamic precision shooting evaluative team (SET), and dynamic precision shooting non-evaluative team (NET), differentiated by the evaluation of the shooting test necessary for the ratification of access to the special corps. The last subgroup was represented by office clerks, used as control group (CG).

Each member of every group must maintain proficiency in different tasks, such as marksmanship and public security interventions, including specialized training and experience in performing discrimination tasks in high-threat environments.

Subjects were selected randomly to reduce the possibility of bias in self-selection, and participation was on a voluntary basis. All workers were recruited for their own particular tasks to the last control of health surveillance. This study was carried out during the Health Surveillance periodical controls according to Italian Legislative Decree 81/2008. All participants agreed to the processing of their personal data and understood that this information was categorized as "sensitive data" and treated in an anonymous and collective way, with scientific methods and for scientific purposes in accordance with the principles of the Declaration of Helsinki [8]. Having received exhaustive information on the study protocol, all participants gave their signed informed consent.

The response rate was $93 \%$, due to refusal to undergo the measurement by six subjects, who were therefore excluded from the study.

For inclusion in the study, a questionnaire investigating anthropometric parameters, such as age, height, weight, and clinical history, including smoking habits, previous illnesses, ongoing medication, and physical activity, was administered to all workers by the occupational medicine physician and barracks nursing staff.

Any previous or current cardiovascular disease, such as recent myocardial infarction, angina pectoris, and ventricular tachycardia, atrial fibrillation, bearers of an implantable defibrillator, and other comorbidities such as decompensated diabetes with organ damage, were adopted as exclusion criteria, as well as a percentage of artefacts greater than $5 \%$ of the registration. Only one of the enrolled subjects was excluded due to exclusion criteria (heart disease).

The measurements and analysis were therefore carried out on a final sample of 105 subjects, distributed as follows in the six subgroups: PT, $n=22$; NSS, $n=16$; NSP, $n=19$; SET, $n=15 ; \mathrm{NET}, n=17 ; \mathrm{CG}, n=15$. No participants were excluded for excessive signal artefacts in the physiological data, or for technical issues, such as those arising from excessive physical motion, weapon use, or experimental failure (i.e., battery drain or insufficient adhesion of the sensors to the subject's skin).

Every participant, in order to avoid any possible acute effect, did not smoke or drink coffee in the four hours prior to the start of registration; however, we considered smoking as a dichotomic variable, taking into account also its widely studied and known chronic effect. 


\subsection{Measurements}

In order to collect the cardiovascular parameters throughout the study, the participants wore a device, snapped onto an adjustable on-board skin conductive electrode belt, i.e., the Zephyr BioHarness 3.0 (Zephyr Technology Corporation, Annapolis, MD, USA-a division of Medtronic-Figure 1) capable of real-time and long-distance recording of various physiological parameters for up to $500 \mathrm{~h}$, for a paltry weight of $89 \mathrm{~g}$ (belt $71 \mathrm{~g}$ and sensor $18 \mathrm{~g}$ ). It captures a range of physiological information, such as heart rate (range: $0-240 \pm 1 \mathrm{BPM}$ ), respiration (range: $0-120 \pm 1 \mathrm{BPM}$ ), body temperature (range: $\left.10-60 \pm 2{ }^{\circ} \mathrm{C}\right)$, movement $\left( \pm 180^{\circ}\right.$ thanks to an accelerometer on three axes, $16 \mathrm{~g}$ with a frequency of $100 \mathrm{~Hz}$ ), one-lead electrocardiography (ECG) (frequency: $250 \mathrm{~Hz}$ ) and, thanks to its on-board calculation algorithms, the estimated VO2max; our analysis focused only on the HRV. In a recent systematic review, Nazari [9] claimed that the Zephyr BioHarness 3.0 device can provide reliable and valid measurements of heart rate across multiple contexts, and that it displayed good agreements with gold standard measurements, as also reported in previous validation studies [10-12].

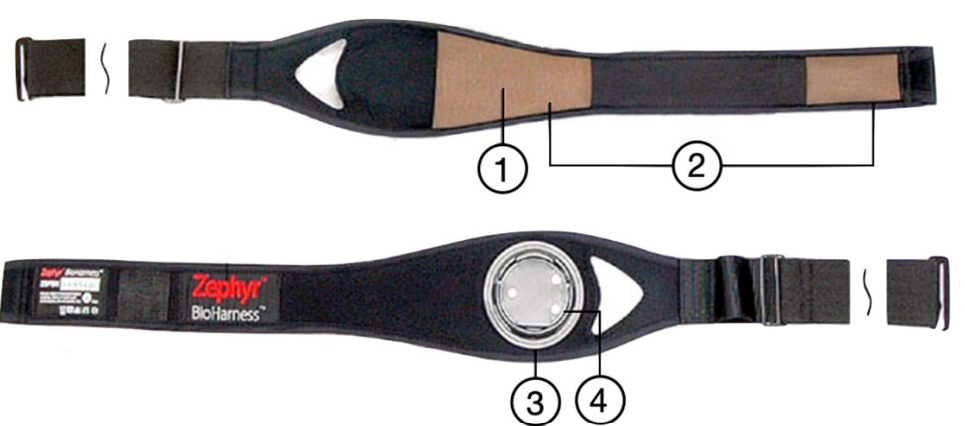
Medtronic Zephyr BioHarness 3 component parts
1. Internal Breathing Rate sensor
2. ECG Sensors
3. Device housing
4. Built-in electrical contacts

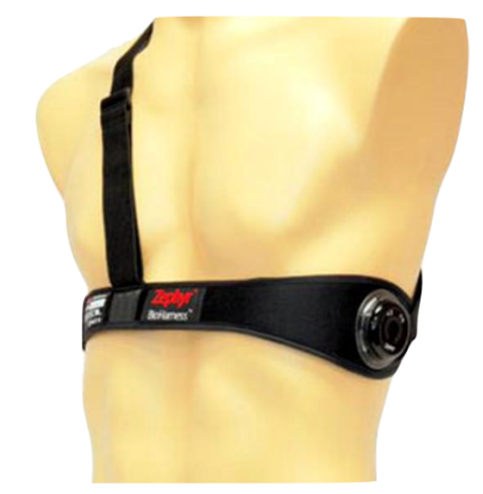

Figure 1. Zephyr BioHarness 3.0 (property of Zephyr Technology Corporation, Annapolis, MD, USA-a division of Medtronic). ECG, electrocardiography.

Before starting the shift, all participants sat in a quiet room for $10 \mathrm{~min}$ in order to assess and register their HRV baseline. Normal RR interval (NN) raw data were extracted with the Zephyr OmniSense Analysis software version 3.9.6 (Zephyr Technology Corporation, Annapolis, MD, USA — a division of Medtronic), converted into a DAT file (extension .dat), and then analyzed with the software Kubios HRV Premium v. 3.3.1, capable of filtering data and removing noise and artefacts, thanks to automated algorithms [13].

Physical activity levels were assessed by the validated Kasari physical activity questionnaire, developed in the 1970s by Kasari [14] and shown to relate to aerobic fitness, i.e., with an increase in frequency, intensity, and time (FIT) of exercise, there is an accompanying increase in the index score and fitness. The FIT index of Kasari quantifies respondents' participation in any form of leisure time physical activity. The questionnaire uses three 
parameters, namely, frequency of exercise, intensity of exercise, and time spent on workout, to calculate the FIT index using the following formula:

FIT index $=($ points for frequency $) \times($ points for intensity $) \times($ points for duration $)$.

A minimum score of 1 and a maximum score of 125 can be achieved. A higher score is indicative of a more physically active person. The Kasari index, thus, may be used to estimate gross energy expenditure (EE) [14,15].

The stress index is the square root, in order to make the index normally distributed, of Baevsky's stress index [16], strongly linked to sympathetic nervous activity, and values of Baevsky's stress index between 50 and 150 are considered normal.

Short- (15 min) and long-term (6 h) Holter ECG recordings were carried out for each subject while performing regular tasks. In detail, monitoring was carried out during skydiving in paratroopers, during night patrolling in NSP, during coordinating activities in the police station (emergency calls sorting, addressing public security interventions) in NSS, during dynamic precision shoot training in the SET and NET subgroups, and during office activity for the CG. Electrocardiograms were continuously recorded for the entire duration of the shift using Zephyr BioHarness 3.0. The HRV parameters given in Table 1 were calculated in the time and frequency domains.

Table 1. HRV parameters on the time and frequency domains.

\begin{tabular}{|c|c|c|c|}
\hline HRV Parameter & SI & Description & Range \\
\hline SDNN & $\mathrm{ms}$ & $\begin{array}{l}\text { Standard deviation of normal-to-normal } \\
\qquad(\mathrm{NN}) \text { intervals }\end{array}$ & \\
\hline RMSSD & $\mathrm{ms}$ & $\begin{array}{l}\text { Root mean square of successive } \\
\text { differences in adjacent NN intervals }\end{array}$ & \\
\hline VLF & $\mathrm{Hz}$ & Very-low-frequency power & $0.003-0.04 \mathrm{~Hz}$ \\
\hline LF & $\mathrm{Hz}$ & Low-frequency power & $0.04-0.15 \mathrm{~Hz}$ \\
\hline HF & $\mathrm{Hz}$ & High-frequency power & $0.15-0.4 \mathrm{~Hz}$ \\
\hline LF/HF & $\mathrm{ms}^{2} / \mathrm{ms}^{2}$ & LF/HF ratio & \\
\hline TP & $\mathrm{Hz}$ & $\begin{array}{l}\text { The variance of NN intervals over the } \\
\text { temporal segment }\end{array}$ & $<0.4 \mathrm{~Hz}$ \\
\hline \multicolumn{4}{|l|}{ Stress index } \\
\hline PNS & & Parasympathetic nervous system activity & \\
\hline SNS & & Sympathetic nervous system activity & \\
\hline
\end{tabular}

Both the sympathetic and parasympathetic branches of the autonomic nervous system (ANS) are involved in the regulation of heart rate (HR). Parasympathetic nervous system (PNS) activity (vagal stimulation) is known to decrease heart rate and to increase heart rate variability. Sympathetic nervous system (SNS) activity has more or less the opposite effect on heart rate and heart rate variability, i.e., it increases HR and decreases HRV. Therefore, HR is lowest and HRV is highest when resting and fully recovered. During stressful situations, instead, sympathetic nervous activity is increased, resting heart rate is elevated, and heart rate variability is decreased.

Parasympathetic cardiac activity is known to decrease heart rate, increase HRV via the enhanced respiratory sinus arrhythmia (RSA) component, and decrease the ratio between lower- and higher-frequency oscillations in HRV time series.

During stress or during high-intensity exercise, much lower PNS index values can be expected.

Sympathetic cardiac activity is known to increase heart rate, decrease HRV, reduce especially quick RSA-related changes in the RR interval, and increase the ratio between lower- and higher-frequency oscillations in HRV data [4,17-19]. 
The interpretation of the SNS index is similar to that of the PNS index. During stress or high-intensity exercise, much higher SNS index values can be expected.

\subsection{Statistical Analysis}

A priori power analysis was not carried out, as the study sample, divided into subgroups constituted by type of work activity, was chosen based on the sample size of the least represented homogeneous group.

Measures of central tendency (mean) and dispersion (standard deviation (SD)) were calculated for all the continuous variables, while prevalence rates were calculated for the categorical variables. Comparisons of the HRV parameters between the categories of workers and between the activity levels (non-active, semi-active, and active activities) were performed using parametric tests (i.e., ANOVAs). The activity level subgroups were classified as follows: non-active (office workers), semi-active (night shift police station officers and night shift patrol), and active (paratroopers, dynamic precision shooting evaluation team, and shooting non-evaluative team).

A Bonferroni post-hoc test was performed to highlight subgroup differences when the results of the ANOVA showed a significant difference. The correlation between variables was tested by Pearson's $r$ coefficient and Spearman's rho coefficient, as appropriate for the variables with a normal (age and BMI) or non-normal distribution (FIT index, smoking habit, and medicament intake), respectively. Normal distribution of all variables of interest was checked by a Kolmogorov-Smirnov test and visual inspection of the curve distribution. We used log-transformed values to ensure normal distribution for frequency domain HRV parameters (very-low-frequency (VLF) power, low-frequency (LF) power, high-frequency (HF) power, and LF/HF ratio). Finally, we used a multivariate analysis by a linear mixed model to test the direct effects on the HRV parameters of job task, BMI, age, smoking habit, physical activity, and drug intake. Finally, to test the effect of the activity levels on the HRV parameters, a multivariate analysis was conducted when considering as factors the activity subgroups (non-active, semi-active, and active activity groups) instead of the job task subgroups. Analyses were conducted using SPSS (v. 25, package for Windows, SPSS Inc., Chicago, IL, USA). An $\alpha$-value of 0.05 indicates statistical significance.

\subsection{Ethical Approval and Consent to Participate}

The technical-scientific committee of the Carabinieri's Health Directorate assessed the research protocol on variability of heart rate in groups of Carabinieri specialized in various tasks of high complexity and psychophysical risk, such as parachute jumping, dynamic evaluation and non-evaluation, and external and internal night work with the use of wearable devices. Considering the experimental nature without drug administration and the adherence to the dictates referred to by the Declaration of Helsinki of the World Medical Association, updated in October 2013, the abovementioned technical-scientific committee authorized the study.

\section{Results}

The characteristics of the study population and the values of the central tendency and dispersion for the investigated HRV parameters in the overall study population are given in Table 2.

The results of the multiple comparisons between the different subgroups showed significant differences for all of the considered HRV parameters (Table 2). The mean age was also significantly different among the subgroups $(p<0.001)$, while BMI was not ( $p=0.117$ ) (Table 3). In addition, comparing the HRV parameters among the activity groups (non-active, semi-active, and active), a significant difference emerged between the nonactive and active groups and between the semi-active and active groups for all of the HRV parameters (Table 4). On the contrary, no significant differences were detected between the non-active and semi-active subgroups. 
Table 2. Characteristics of the study population and the HRV parameters (overall sample $n=105$ ).

\begin{tabular}{|c|c|c|c|c|c|}
\hline \multicolumn{2}{|c|}{ Parameters } & Mean & SD & $n$ & $(\%)$ \\
\hline \multicolumn{2}{|c|}{ Age (years) } & 40.67 & 9.88 & - & - \\
\hline \multicolumn{2}{|c|}{ BMI $\left(\mathrm{kg} / \mathrm{m}^{2}\right)$} & 25.99 & 2.63 & - & - \\
\hline \multirow{2}{*}{ Smoking habit } & Smokers & - & - & 19 & 18.1 \\
\hline & Non-smokers & - & - & 86 & 81.9 \\
\hline \multirow{2}{*}{ Medications } & Yes & - & - & 12 & 11.4 \\
\hline & No & - & - & 93 & 88.6 \\
\hline \multirow{2}{*}{ Physical activity } & Yes & - & - & 93 & 88.6 \\
\hline & No & - & - & 12 & 11.4 \\
\hline \multicolumn{2}{|c|}{ Physical activity level (FIT) } & 32.52 & 25.68 & - & - \\
\hline \multicolumn{2}{|c|}{ Mean HR (bpm) } & 89.42 & 23.54 & - & - \\
\hline \multicolumn{2}{|c|}{ SDNN (ms) } & 35.54 & 15.40 & - & - \\
\hline \multicolumn{2}{|c|}{ RMSSD } & 24.79 & 16.32 & - & - \\
\hline \multicolumn{2}{|c|}{ VLF power * } & 2.07 & 0.39 & - & - \\
\hline \multicolumn{2}{|c|}{ LF power * } & 2.85 & 0.44 & - & - \\
\hline \multicolumn{2}{|c|}{ HF power * } & 2.13 & 0.61 & - & - \\
\hline \multicolumn{2}{|c|}{ LF/HF ratio * } & 0.72 & 0.29 & - & - \\
\hline \multicolumn{2}{|c|}{ Stress index } & 11.43 & 5.95 & - & - \\
\hline \multicolumn{2}{|c|}{ PNS } & -1.58 & 1.37 & - & - \\
\hline \multicolumn{2}{|c|}{ SNS } & 2.11 & 2.61 & - & - \\
\hline
\end{tabular}

Table 3. HRV parameters stratified by job task and results of the comparisons among the subgroups by ANOVA.

\begin{tabular}{|c|c|c|c|c|c|c|c|c|c|c|c|c|c|c|}
\hline & \multicolumn{2}{|c|}{ CG } & \multicolumn{2}{|c|}{ NSP } & \multicolumn{2}{|c|}{ NSS } & \multicolumn{2}{|c|}{ PT } & \multicolumn{2}{|c|}{ NET } & \multicolumn{2}{|c|}{ SET } & \multirow[b]{2}{*}{$\mathbf{F}$} & \multirow[b]{2}{*}{$p$} \\
\hline & Mean & SD & Mean & SD & Mean & SD & Mean & SD & Mean & SD & Mean & SD & & \\
\hline Age & 37.33 & 7.83 & 46.32 & 6.50 & 47.1 & 5.21 & 46.95 & 7.97 & 35.24 & 7.16 & 27.06 & 2.02 & 27.665 & $<0.001$ \\
\hline BMI & 25.20 & 2.17 & 27.44 & 3.62 & 26.28 & 2.71 & 25.73 & 1.69 & 25.75 & 2.84 & 25.31 & 2.00 & 1.813 & 0.117 \\
\hline Mean HR & 71.60 & 10.40 & 71.32 & 9.72 & 63.25 & 7.05 & 111.50 & 13.76 & 107.00 & 18.53 & 104.75 & 13 & 51.747 & $<0.001$ \\
\hline SDNN & 48.83 & 13.07 & 41.62 & 14.57 & 44,03 & 13.30 & 24.80 & 10.85 & 26.10 & 12.98 & 32.14 & 11.17 & 10.878 & $<0.001$ \\
\hline RMSSD & 38.74 & 19.05 & 31.90 & 16.88 & 35.27 & 13.70 & 12.34 & 6.50 & 15.82 & 10.49 & 19.46 & 8.76 & 12.789 & $<0.001$ \\
\hline VLF power & 2.7 & 0.17 & 2.23 & 0.24 & 2.31 & 0.27 & 1.80 & 0.38 & 1,82 & 0.46 & 1.99 & 0.31 & 10.376 & $<0.001$ \\
\hline LF power & 3.15 & 0.23 & 3.02 & 0.28 & 3.03 & 0.31 & 2.65 & 0.45 & 2,51 & 0.60 & 2.81 & 0.32 & 6.991 & $<0.001$ \\
\hline HF power & 2.57 & 0.42 & 2.35 & 0.50 & 2.42 & 0.46 & 1.73 & 0.52 & 1,77 & 0.78 & 2.07 & 0.44 & 7.669 & $<0.001$ \\
\hline LF/HF ratio & 0.58 & 0.37 & 0.67 & 0.33 & 0.61 & 0.28 & 0.92 & 0.55 & 0.74 & 0.26 & 0.74 & 0.23 & 3.695 & 0.004 \\
\hline Stress index & 6.72 & 1.84 & 7.42 & 2.54 & 6.41 & 2.68 & 15.20 & 3.72 & 17.86 & 6.41 & 13.61 & 4.65 & 27.332 & $<0.001$ \\
\hline PNS & -0.46 & 0.93 & -0.64 & 0.89 & -0.05 & 0.71 & -2.80 & 0.58 & -2.52 & 0.86 & -2.61 & 0.54 & 47.706 & $<0.001$ \\
\hline SNS & 0.02 & 1.01 & 0.12 & 0.98 & -0.58 & 0.76 & 4.26 & 1.58 & 4.38 & 2.46 & 3.76 & 1.45 & 43.869 & $<0.001$ \\
\hline
\end{tabular}

The results of the Bonferroni post-hoc test for mean HR did show that the mean HR was significantly higher in the PT $(p<0.001)$, SET $(p<0.001)$, and NET $(p<0.001)$ subgroups with respect to the control group, while they did not show any significant difference between the control group and external and internal night activity $(p>0.05)$. Similar results were obtained for standard deviation of NN intervals (SDNN), root mean square of successive differences in adjacent NN intervals (RMSSD), VLF power, HF power, HF power, and PNS index, which were significantly higher in the control group with 
respect to the PT, SET, and NET subgroups, but not with respect to night work (both internal and external) (Table 5).

Table 4. The HRV parameters stratified by activity levels and results of the comparisons among the subgroups by ANOVA.

\begin{tabular}{|c|c|c|c|c|c|c|c|c|}
\hline & \multicolumn{2}{|c|}{ Non-Active Activities } & \multicolumn{2}{|c|}{ Semi-Active Activities } & \multicolumn{2}{|c|}{ Active Activities } & \multirow[b]{2}{*}{$\mathbf{F}$} & \multirow[b]{2}{*}{$p$} \\
\hline & Mean & SD & Mean & SD & Mean & SD & & \\
\hline Age & 37.33 & 7.83 & 47 & 5.906 & 38 & 10.623 & 13.336 & $<0.001$ \\
\hline BMI & 25.20 & 2.17 & 26.91 & 3.24 & 25.61 & 2.18 & 3.528 & 0.033 \\
\hline Mean HR & 71.60 & 10.40 & 67.63 & 9.412 & 108.15 & 15.316 & 122.218 & $<0.001$ \\
\hline SDNN & 48.83 & 13.07 & 42.72 & 13.86 & 27.34 & 11.95 & 25.205 & $<0.001$ \\
\hline RMSSD & 38.74 & 19.05 & 33.44 & 15,38 & 15.49 & 8.97 & 30.184 & $<0.001$ \\
\hline VLF power * & 2.37 & 0.17 & 2.27 & 0.25 & 1.86 & 0.40 & 23.683 & $<0.001$ \\
\hline LF power * & 3.15 & 0.23 & 3.02 & 0.29 & 2.65 & 0.48 & 14.694 & $<0.001$ \\
\hline HF power * & 2.57 & 0.42 & 2.38 & 0.48 & 1.84 & 0.60 & 16.777 & $<0.001$ \\
\hline LF/HF ratio * & 0.58 & 0.37 & 0.64 & 0.30 & 0.81 & 0.23 & 6.247 & 0.003 \\
\hline Stress index & 6.72 & 1.84 & 6.96 & 2.62 & 15.56 & 5.19 & 58.826 & $<0.001$ \\
\hline PNS & -0.46 & 0.93 & -0.37 & 0.85 & -2.66 & 0.67 & 111.932 & $<0.001$ \\
\hline SNS & 0.02 & 1.01 & -0.20 & 0.94 & 4.15 & 1.86 & 107.292 & $<0.001$ \\
\hline
\end{tabular}

Table 5. Bonferroni post-hoc test results comparing the HRV parameters between the control group and the other categories.

\begin{tabular}{|c|c|c|c|c|c|}
\hline $\begin{array}{l}\text { HRV Parameter } \\
\text { Control Group }\end{array}$ & vs. NSP & vs. NSS & vs. PT & vs. NET & vs. SET \\
\hline HR & $x$ & $x$ & $\checkmark$ & $\checkmark$ & $\checkmark$ \\
\hline SDNN & $x$ & $x$ & $\checkmark$ & $\checkmark$ & $p=0.006$ \\
\hline RMSSD & $x$ & $x$ & $\checkmark$ & $\checkmark$ & $p=0.001$ \\
\hline VLF & $x$ & $x$ & $\checkmark$ & $\checkmark$ & $p=0.003$ \\
\hline LF power & $x$ & $x$ & $\checkmark$ & $\checkmark$ & $p=0.006$ \\
\hline HF power & $x$ & $x$ & $p=0.003$ & $p=0.033$ & $p=0.043$ \\
\hline LF/HF ratio & $x$ & $x$ & $x$ & $x$ & $x$ \\
\hline Stress index & $x$ & $x$ & $\checkmark$ & $\checkmark$ & $\checkmark$ \\
\hline PNS index & $x$ & $x$ & $\checkmark$ & $\checkmark$ & $\checkmark$ \\
\hline SNS index & $x$ & $x$ & $\checkmark$ & $\checkmark$ & $\checkmark$ \\
\hline
\end{tabular}

Legend: $\mathbf{x} p>0.05 ; \checkmark p<0.001$.

On the contrary, the stress and SNS indices were significantly lower in the control group with respect to evaluative and non-evaluative shooting training and with paratroopers, but not with night workers (Table 6). No significant differences were found when comparing the HF/LF ratio between the control group and the other subgroups $(p>0.05)$.

The independent variables supposed to affect HRV parameters showed a weak significant correlation between age and BMI $(r=0.35 ; p<0.001)$ and a weak inverse correlation between age and FIT index (rho $=-0.28 ; p=0.004)$. No significant correlation appeared between the other variables of interest (data not shown in table).

The results of the multivariate linear mixed model predicting the HRV parameters by study subgroup and covariates showed that belonging to the subgroup of paratroopers and evaluative and non-evaluative training significantly decreased the HRV parameters SDNN, RMSSD, VLF power, LF power, HF power, and PNS index, while increased the 
mean HR, stress index, and SNS index (Tables 7 and 8). Taking medicaments significantly decreased the mean HR $(p=0.08)$ and SNS index $(p=0.019)$, while it increased the VLF power $(p=0.026)$ (Tables 7 and 8$)$. Increasing age determined an effect on decreasing the SDNN, RMSSD, VLF power, LF power, and HF power, while it increased the LF/HF ratio at a marginal level of significance $(p=0.052)$. No significant effects were found for age on the mean HR, stress index, PNS index, and SNS index. Smoking habit and BMI did not show any influence on the HRV parameters. Finally, physical activity levels, measured as th FIT index, were only marginally significant on decreasing the mean $\mathrm{HR}(p=0.061)$ and SNS index $(p=0.082)$ and increasing the PNS index $(p=0.085)$. Similar results were obtained when considering the activity groups as independent variables, instead of the job task groups (Supplementary Table S1).

Table 6. Bonferroni post-hoc test results comparing HRV parameters between the control group and other activity categories.

\begin{tabular}{cccc}
\hline $\begin{array}{c}\text { HRV Parameter Control Group } \\
=\text { Non Active Activities }\end{array}$ & $\begin{array}{c}\text { vs. Semi-Active } \\
\text { Activities }\end{array}$ & $\begin{array}{c}\text { vs. Active } \\
\text { Activities }\end{array}$ & $\begin{array}{c}\text { Semi-Active vs. } \\
\text { Active Activities }\end{array}$ \\
\hline HR & $\boldsymbol{x}$ & $\checkmark$ & $\checkmark$ \\
\hline SDNN & $\boldsymbol{x}$ & $\checkmark$ & $\checkmark$ \\
\hline RMSSD & $\boldsymbol{x}$ & $\checkmark$ & $\checkmark$ \\
\hline VLF & $\boldsymbol{x}$ & $\checkmark$ & $\checkmark$ \\
\hline LF power & $\boldsymbol{x}$ & $\checkmark$ & $p=0.003$ \\
\hline HF power & $\boldsymbol{x}$ & $p=0.016$ & $p=0.017$ \\
\hline LF/HF ratio & $\mathbf{x}$ & $\checkmark$ & $\checkmark$ \\
\hline Stress index & $\boldsymbol{x}$ & $\checkmark$ & $\checkmark$ \\
\hline PNS index & $\boldsymbol{x}$ & $\checkmark$ & $\checkmark$ \\
\hline SNS index & & &
\end{tabular}

Legend: $\mathbf{x} p>0.05 ; \checkmark p<0.001$

Table 7. Multivariate linear mixed model results predicting the HRV parameters by study subgroups and covariates. The predictors included the five study subgroups (part I).

\begin{tabular}{|c|c|c|c|c|c|c|c|c|c|c|c|}
\hline \multirow{2}{*}{\multicolumn{2}{|c|}{ Predictors }} & \multicolumn{2}{|c|}{$\begin{array}{l}\text { Model } 1 \\
\text { HR }\end{array}$} & \multicolumn{2}{|c|}{$\begin{array}{l}\text { Model } 2 \\
\text { SDNN }\end{array}$} & \multicolumn{2}{|c|}{$\begin{array}{l}\text { Model } 3 \\
\text { RMSSD }\end{array}$} & \multicolumn{2}{|c|}{$\begin{array}{c}\text { Model } 4 \\
\text { VLF Power }\end{array}$} & \multicolumn{2}{|c|}{$\begin{array}{l}\text { Model } 5 \\
\text { LF Power }\end{array}$} \\
\hline & & Beta & $p$-Value & Beta & $p$-Value & Beta & $p$-Value & Beta & $p$-Value & Beta & $p$-Value \\
\hline \multicolumn{2}{|c|}{ Age } & -0.255 & 0.195 & -0.589 & 0.002 & -0.492 & 0.018 & -0.011 & 0.028 & -0.018 & 0.003 \\
\hline \multicolumn{2}{|c|}{ BMI } & 0.497 & 0.302 & -0.172 & 0.718 & -0.034 & 0.947 & -0.005 & 0.659 & -0.011 & 0.458 \\
\hline \multirow{6}{*}{$\begin{array}{l}\text { Study } \\
\text { group }\end{array}$} & $\begin{array}{c}\mathrm{CG} \\
\text { (ref) }\end{array}$ & $\backslash$ & 1 & 1 & 1 & 1 & 1 & $\backslash$ & 1 & 1 & $\backslash$ \\
\hline & NSP & 1.042 & 0.813 & -1.093 & 0.802 & -1.877 & 0.687 & -0.030 & 0.794 & 0.052 & 0.698 \\
\hline & NSS & -6.900 & 0.159 & 3.058 & 0.527 & 3.007 & 0.560 & 0.071 & 0.572 & 0.106 & 0.474 \\
\hline & PT & 41.957 & $<0.001$ & -17.719 & $<0.001$ & -21.199 & $<0.001$ & -0.462 & $<0.001$ & -0.318 & 0.014 \\
\hline & SET & 35.328 & $<0.001$ & -24.234 & $<0.001$ & -24.062 & $<0.001$ & -0.595 & $<0.001$ & -0.692 & $<0.001$ \\
\hline & NET & 31.416 & $<0.001$ & -22.727 & $<0.001$ & -24.246 & $<0.001$ & -0.514 & $<0.001$ & -0.529 & $<0.001$ \\
\hline \multicolumn{2}{|c|}{ Smoking habit } & 1.454 & 0.643 & -3.514 & 0.258 & -2.027 & 0.540 & -0.042 & 0.604 & -0.106 & 0.262 \\
\hline \multicolumn{2}{|c|}{$\begin{array}{l}\text { Physical activity } \\
\text { (FIT) }\end{array}$} & -0.092 & 0.061 & 0.054 & 0.271 & 0.040 & 0.438 & 0.002 & 0.139 & 0.002 & 0.290 \\
\hline \multicolumn{2}{|c|}{ Medications } & -9.839 & 0.008 & 3.987 & 0.277 & 1.721 & 0.660 & 0.213 & 0.026 & 0.170 & 0.130 \\
\hline
\end{tabular}


Table 8. Multivariate linear mixed model results predicting HRV parameters by study subgroups and covariates. Predictors included the five study subgroups (part II).

\begin{tabular}{|c|c|c|c|c|c|c|c|c|c|c|c|}
\hline \multirow{2}{*}{\multicolumn{2}{|c|}{ Predictors }} & \multicolumn{2}{|c|}{$\begin{array}{c}\text { Model } 6 \\
\text { Dependent Variable: } \\
\text { HF Power }\end{array}$} & \multicolumn{2}{|c|}{$\begin{array}{c}\text { Model } 7 \\
\text { Dependent Variable: } \\
\text { HF/LF Ratio } \\
\end{array}$} & \multicolumn{2}{|c|}{$\begin{array}{c}\text { Model } 8 \\
\text { Dependent Variable: } \\
\text { Stress Index }\end{array}$} & \multicolumn{2}{|c|}{$\begin{array}{c}\text { Model } 9 \\
\text { Dependent Variable: } \\
\text { PNS Index } \\
\end{array}$} & \multicolumn{2}{|c|}{$\begin{array}{c}\text { Model 10 } \\
\text { Dependent Variable: } \\
\text { SNS Index }\end{array}$} \\
\hline & & Beta & $p$-Value & Beta & $p$-Value & Beta & $p$-Value & Beta & $p$-Value & Beta & $p$-Value \\
\hline & & -0.026 & 0.002 & 0.009 & 0.052 & 0.032 & 0.605 & -0.006 & 0.638 & -0.012 & 0.623 \\
\hline & & -0.002 & 0.913 & -0.009 & 0.387 & 0.240 & 0.114 & -0.016 & 0.593 & 0.074 & 0.194 \\
\hline \multirow{6}{*}{$\begin{array}{l}\text { Study } \\
\text { group }\end{array}$} & CG (ref) & 1 & 1 & 1 & 1 & 1 & 1 & 1 & 1 & 1 & $\backslash$ \\
\hline & NSP & 0.033 & 0.859 & 0.021 & 0.830 & -0.142 & 0.918 & -0.076 & 0.780 & 0.047 & 0.928 \\
\hline & NSS & 0.171 & 0.408 & -0.068 & 0.535 & -1.216 & 0.429 & 0.565 & 0.061 & -0.658 & 0.259 \\
\hline & PT & -0.573 & 0.002 & 0.253 & 0.009 & 7.927 & $<0.001$ & -2.251 & $<0.001$ & 4.290 & $<0.001$ \\
\hline & SET & -0.872 & $<0.001$ & 0.181 & 0.057 & 11.337 & $<0.001$ & -2.090 & $<0.001$ & 4.411 & $<0.001$ \\
\hline & NET & -0.775 & $<0.001$ & 0.251 & 0.019 & 7.296 & $<0.001$ & -2.237 & $<0.001$ & 3.704 & $<0.001$ \\
\hline \multicolumn{2}{|c|}{ Smoking habit } & -0.042 & 0.754 & -0.063 & 0.370 & 1.224 & 0.215 & -0.090 & 0.643 & 0.228 & 0.542 \\
\hline \multicolumn{2}{|c|}{$\begin{array}{l}\text { Physical activity } \\
\text { (FIT) }\end{array}$} & 0.002 & 0.309 & -0.001 & 0.648 & -0.018 & 0.232 & 0.005 & 0.082 & -0.010 & 0.085 \\
\hline \multicolumn{2}{|c|}{ Medications } & 0.114 & 0.467 & 0.060 & 0.468 & -2.211 & 0.058 & 0.421 & 0.065 & -1.038 & 0.019 \\
\hline
\end{tabular}

\section{Discussion}

By means of this observational study, our aim was to assess the changes in the HRV parameters in highly psychophysical demanding tasks, such as those of an elite public security special corps. We investigated the effect of various occupational factors such as acute stress, night shift working, and highly demanding training activity on the autonomic regulation of the cardiac function, finding a significant effect of more demanding activities when compared to those exposed to less external stimuli, such as office activities.

HRV is a simple, non-invasive, analyzable in real time, and highly reproducible measure that represents a significant bioindicator for assessing a person's health and physical condition. Heart rate variation is controlled by a primitive part of the nervous system called the ANS, which works regardless of desire and regulates, in addition to the heart rate, blood pressure, breathing, and digestion. The ANS is subdivided into two large components, i.e., the sympathetic and the parasympathetic nervous system, also known as the fight-or-flight mechanism and the relaxation response. The brain is constantly processing information in a region called the hypothalamus. The hypothalamus, through the ANS, sends signals to the rest of the body to either stimulate or relax different functions. In the case of persistent instigators such as stress, poor sleep, unhealthy diet, dysfunctional relationships, isolation or solitude, and lack of exercise, this balance may be disrupted.

Higher HRV levels are correlated to adaptability and positive indications of health, such as greater cardiovascular fitness and greater resilience to stress, whereas lower HRV suggests insufficient adaptation and negative indications of health. Research into respiration and heart rate to maximize heart rate variability has been a major focal point in biofeedback for several decades. HRV is nowadays also a prevalent feature in such biofeedback therapies for health, relaxation, and optimal performance, either with respiration rate, ECG, and blood volume pulse (BVP) [20,21].

HRV is routinely used in clinical medicine, for example, in prognostication after myocardial infarction or even in sports medicine in preventing over-training in pro- or amateur athletes [22]. Additionally, HRV parameters have been widely used in occupational medicine, to evaluate the effect of various work exposure on the cardiovascular system [23]. As studies have delved deeper into the meaning and controls of heart rate variability, newer statistical measures and interpretations of well-being have emerged over time [24,25].

Previous studies reported that age is associated with an SDNN and RMSSD and, specifically, that a negative relationship of age with HRV indicates that proper maintenance of cardiac autonomic nervous system function can be associated with better cardiovascular 
health and, therefore, longevity. Our results are in line with the findings reported in previous studies [26,27].

No associations were found between smoking habit and the HRV parameters, such as SDNN and RMSSD, possibly due to the smoking ban during work activity, so that an acute effect of smoke was not detectable, while a chronic effect on HRV is still questionable [28-30].

In spite of what was expected, night shift working did not influence the HRV parameters, showing no statistically significant differences between the patrolling (NSP) and station-based (NSS) groups compared to the control group. In the literature, in fact, several studies have shown altered circadian rhythms of HRV in night shift workers, which cause imbalance in the autonomic nervous system, increasing the risk of cardiovascular diseases [23,31-34].

As previously reported, highly demanding work tasks, e.g., those carried out by paratroopers, dynamic precision shooting evaluative teams, and dynamic precision shooting non-evaluative teams, for which a high level of concentration and precision with minimum allowed margins of errors required, particularly during skydive free fall, imply significantly higher stress and SNS indices than the control group, represented by white-collar workers (office clerks). This was also corroborated, on the contrary, by decreased values of vagal function represented by RMSSD, HF power, and PNS [35-37].

Our findings highlight that nonsteroidal anti-inflammatory drugs (NSAIDs) seem to be connected to the sympathetic component, as evidenced by reductions in HR and the SNS index. Our results, however, do not allow us to reach any conclusion because of the small number of subjects taking these medications [38-40].

BMI did not show any influence on the HRV parameters, in contrast to what has been shown in some studies. Further epidemiological studies on larger samples are thus required to better understand and define the role of these modifiable risk factors in influencing HRV parameters [41,42].

Physical activity levels, measured as the FIT index, despite being only marginally significant on decreasing the mean HR and SNS index, highlighted the key autonomic cardiac regulation, connected to the sympathetic component, as already widely supported in the literature. We can therefore conclude that physical activity may play an important role in the prevention of cardiovascular diseases, as well as decreasing sympathetic nervous activity [43-46].

Some limitations affected the present study. First, due to the cross-sectional study design, it is not possible to make inferences about the consequences of the highlighted HRV changes. Second, we investigated a selected population of a special force, so a possible healthy worker effect has to be taken into consideration in the interpretation of the results. Third, we did not consider as an influencing variable the time of the last meal with respect to the start of HRV parameter recording. Finally, other work exposures not considered in the study could have an effect on the HRV parameters [27,47-51].

In order to investigate a possible effect of adaptability due to experience, when stratifying HRV parameters by age, we found significant differences between the lowest age group (18-30 years) and the third age group (41-50 years) for the stress index ( $p=0.018)$, the PNS index $(p=0.003)$, and the SNS index $(p=0.002)$. These results might suggest a plausible effect of adaptability provided by the job experience [52]. The adaptability effect needs further efforts to be properly evaluated in future research, also taking into account other factors such as job seniority, task seniority, and work ability index. Further investigations could lead to clarifying these aspects.

Despite such limitations, indeed, HRV can be a powerful tool in the hands of occupational medicine physicians in order to promote health, alongside quitting smoking and a healthy diet, because a decreased HRV, especially during the daytime, goes along with increased cardiovascular risks for both CHDs and CVDs, such as stroke, as reported in some previous studies. In fact, giving up smoking, physical exercise, and weight loss are all associated with increased HRV. Dietary changes, including the consumption of fruit and vegetables and the intake of omega- 3 fatty acids and vitamin $\mathrm{D}$, by means of fish or nut consumption, are also effective approaches for which there is some evidence linking them to increased HRV. 


\section{Conclusions}

HRV indices represent a valid tool for the occupational physician to assess cardiac response to various occupational factors known to affect physical and psychological health, especially when acting with some modifiable and non-modifiable risk factors such as being overweight, smoking, physical inactivity, and increasing age. In addition, HRV assessment can represent a useful tool in the health monitoring of specific groups of workers, such as those engaged in special force activities or in specific training campaigns, such as parachuting and dynamic precision shooting [53].

The study of HRV parameters is thus a useful tool for occupational physicians, both for addressing work suitability assessments and also for filling in some lacunae such as return to work issues, i.e., after a long absence due to injury or illness [54], to be considered as being aimed at monitoring the subject's physiological parameters, and not at the diagnosis of any pathological condition, which should always be the task of medical specialists [55].

Our findings have highlighted how highly demanding work activities can influence autonomic cardiac regulation and, therefore, also the cardiovascular health of workers and their ability to cope with stressful conditions.

Our findings further demonstrate that tracking HRV may represent a powerful tool to motivate behavioral and lifestyle changes, which is thus far not available, even for excessive costs in past decades, to occupational physicians in the management of fitness for work-military personnel in this case-or for collecting information on vital signs during certain physical activities, such as parachuting or shooting tests. Thanks to the results obtained herein, we can assert that, although we believe it is always necessary to expand the case series under study, the evaluation of HRV parameters can be implemented in health surveillance protocols prior to the assignment of a worker to a specific highly demanding task or work activity.

HRV measurements can help create more awareness about one's lifestyle and habits and how behavior affects one's nervous system and bodily functions. While it obviously cannot help to avoid stressful life and work situations, if properly trained, HRV could help to understand how to cope in a healthier way.

Our results also provide useful information on how the use of personal wearable devices can contribute to find new insights on the response of cardiac autonomic control to stressful stimuli from the workplace in order to reach a sustainable development able to include all worker categories when exposed to various work-related stressful conditions [56-58].

The use of HRV in occupational medicine is not intended as a tool for specialist management, which is certainly not the responsibility of occupational physicians, but for cardiologists or sports medicine physicians, but rather as a tool for managing the suitability to be able to carry out certain job activities, as already discussed in the scientific literature, and that a multidisciplinary approach (occupational physicians, sports medicine physicians, and cardiologists) is essential.

Further studies are needed to better understand the role of HRV as a tool for assessing and promoting occupational health and safety, also through the use of validated wearable devices, which represent a relatively less expensive and easy-to-use solution compared to more sophisticated medical instrumentation.

Supplementary Materials: The following are available online at https:/ /www.mdpi.com/article/10 $.3390 /$ su13073867/s1, Table S1: Multivariate linear mixed model results predicting HRV parameters by study sub-groups and covariates. Predictors included the three subgroups by physical activity.

Author Contributions: Conceptualization, G.G., A.B. (Antonio Baldassarre), N.M. and G.A.; methodology, A.B. (Antonio Baldassarre) and L.I.L.; investigation: M.P., M.N. and A.B. (Antonio Brancazio); resources: A.B. (Antonio Baldassarre) and L.I.L.; writing-original draft: A.B. (Antonio Baldassarre) and G.G.; writing-review editing: A.B. (Antonio Baldassarre) and L.I.L.; supervision: N.M., A.T. and G.A.; project administration: G.A. and N.M. All authors have read and agreed to the published version of the manuscript.

Funding: This research received no external funding. 
Institutional Review Board Statement: The study was conducted according to the guidelines of the Declaration of Helsinki, and approved by the technical-scientific committee of the Carabinieri's Health Directorate.

Informed Consent Statement: Informed consent was obtained from all subjects involved in the study.

Data Availability Statement: The datasets used and/or analyzed during the current study are available from the corresponding author on reasonable request.

Acknowledgments: The authors thank the 1st Paratrooper Regiment "Tuscania," Carabinieri, Italian Ministry of Defense, Livorno.

Conflicts of Interest: The authors declare that they have no conflict of interest.

\section{References}

1. Cowan, M.J. Measurement of Heart Rate Variability. West. J. Nurs. Res. 1995, 17, 32-48. [CrossRef] [PubMed]

2. Pinna, G.D.; Maestri, R.; Di Cesare, A.; Colombo, R.; Minuco, G. The accuracy of power-spectrum analysis of heart-rate variability from annotated RR lists generated by Holter systems. Physiol. Meas. 1994, 15, 163-179. [CrossRef] [PubMed]

3. Schäfer, A.; Vagedes, J. How accurate is pulse rate variability as an estimate of heart rate variability? Int. J. Cardiol. 2013, 166, 15-29. [CrossRef]

4. Malik, M.; Bigger, J.T.; Camm, A.J.; Kleiger, R.E.; Malliani, A.; Moss, A.J.; Schwartz, P.J. Heart rate variability: Standards of measurement, physiological interpretation, and clinical use. Eur. Hear. J. 1996, 17, 354-381. [CrossRef]

5. Buccelletti, E.; Gilardi, E.; Scaini, E.; Galiuto, L.; Persiani, R.; Biondi, A.; Basile, F.; Silveri, N.G. Heart rate variability and myocardial infarction: Systematic literature review and metanalysis. Eur. Rev. Med Pharmacol. Sci. 2009, 13, $299-307$.

6. Di Fabio, A. The Psychology of Sustainability and Sustainable Development for Well-Being in Organizations. Front. Psychol. 2017, 8, 1534. [CrossRef]

7. Di Fabio, A. Positive Healthy Organizations: Promoting Well-Being, Meaningfulness, and Sustainability in Organizations. Front. Psychol. 2017, 8, 1938. [CrossRef] [PubMed]

8. World Medical Association. World Medical Association Declaration of Helsinki: Ethical principles for medical research involving human subjects. JAMA 2013, 310, 2191-2194. [CrossRef]

9. Nazari, G.; Bobos, P.; MacDermid, J.C.; Sinden, K.E.; Richardson, J.; Tang, A. Psychometric properties of the Zephyr bioharness device: A systematic review. BMC Sports Sci. Med. Rehabil. 2018, 10, 1-8. [CrossRef]

10. Johnstone, J.A.; Ford, P.A.; Hughes, G.; Watson, T.; Mitchell, A.C.; Garrett, A.T. Field based reliability and validity of the bioharness ${ }^{\mathrm{TM}}$ multivariable monitoring device. J. Sports Sci. Med. 2012, 11, 10.

11. Nazari, G.; MacDermid, J.C. Minimal Detectable Change Thresholds and Responsiveness of Zephyr Bioharness and Fitbit Charge Devices. J. Strength Cond. Res. 2020, 34, 257-263. [CrossRef] [PubMed]

12. Nazari, G.; MacDermid, J.C.; Sinden, K.E.; Richardson, J.; Tang, A. Reliability of Zephyr Bioharness and Fitbit Charge Measures of Heart Rate and Activity at Rest, During the Modified Canadian Aerobic Fitness Test, and Recovery. J. Strength Cond. Res. 2019, 33, 559-571. [CrossRef]

13. Tarvainen, M.P.; Niskanen, J.-P.; Lipponen, J.A.; Ranta-Aho, P.O.; Karjalainen, P.A. Kubios HRV—Heart rate variability analysis software. Comput. Methods Programs Biomed. 2014, 113, 210-220. [CrossRef] [PubMed]

14. Grant, C.C.; Janse van Rensburg, D.C.; Pepper, M.S.; Du Toit, P.J.; Wood, P.S.; Ker, J.; Krüger, P.E.; Grobbelaar, C.W.; Nolte, K.; Fletcher, F.; et al. The correlation between the health-related fitness of healthy participants measured at home as op-posed to fitness measured by sport scientists in a laboratory. S. Afr. Fam. Pract. 2014, 56, 235-239. [CrossRef]

15. Dreyer, L.I.; Strydom, G.L.; Van Der Merwe, S. The relationships between physical activity, lifestyle and health. ICHPER J. 1997, $33,15-18$.

16. Baevsky, R.M.; Berseneva, A.P. Methodical Recommendations-Use Kardivar System for Determination of the Stress Level and Estimation of the Body Adaptability—Standards of Measurements and Physiological Interpretation; Moscow, 2008. Available online: http:/ / www. kardivar.eu/en/index.php?controller=attachment\&id_attachment=53 (accessed on 11 January 2021)

17. Acharya, U.R.; Joseph, K.P.; Kannathal, N.; Lim, C.M.; Suri, J.S. Heart rate variability: A review. Med Biol. Eng. Comput. 2006, 44, 1031-1051. [CrossRef] [PubMed]

18. Nunan, D.; Sandercock, G.R.H.; Brodie, D.A. A Quantitative Systematic Review of Normal Values for Short-Term Heart Rate Variability in Healthy Adults. Pacing Clin. Electrophysiol. 2010, 33, 1407-1417. [CrossRef]

19. He, Z. The control mechanisms of heart rate dynamics in a new heart rate nonlinear time series model. Sci. Rep. 2020, 10, 1-21. [CrossRef]

20. Kristal-Boneh, E.; Raifel, M.; Froom, P.; Ribak, J. Heart rate variability in health and disease. Scand. J. Work. Environ. Heal. 1995, 21, 85-95. [CrossRef]

21. Togo, F.; Takahashi, M. Heart Rate Variability in Occupational Health -A Systematic Review. Ind. Health 2009, 47, 589-602. [CrossRef]

22. Grant, C.C.; Janse van Rensburg, D.C.; Grant, R. The effect of different types of sports on resting heart rate variability and au-tonomic nervous system balance. Afr. J. Phys. Health Educ. Recreat. Danc. 2008, 14. 
23. Lecca, L.I.; Setzu, D.; Del Rio, A.; Campagna, M.; Cocco, P.; Meloni, M. Indexes of cardiac autonomic profile detected with short term Holter ECG in health care shift workers: A cross sectional study. La Med. Lav. 2019, 110, 437-445.

24. Steffen, P.R.; Austin, T.; DeBarros, A.; Brown, T. The Impact of Resonance Frequency Breathing on Measures of Heart Rate Variability, Blood Pressure, and Mood. Front. Public Health 2017, 5, 222. [CrossRef] [PubMed]

25. Lehrer, P.M.; Vaschillo, E.; Vaschillo, B. Resonant frequency biofeedback training to increase cardiac variability: Ra-tionale and manual for training. Appl. Psychophysiol. Biofeedback 2000, 25, 177-191. [CrossRef]

26. Järvelin-Pasanen, S.; Sinikallio, S.; Tarvainen, M.P. Heart rate variability and occupational stress-systematic review. Ind. Heal. 2018, 56, 500-511. [CrossRef] [PubMed]

27. Kang, D.; Kim, Y.; Kim, J.; Hwang, Y.; Cho, B.; Hong, T.; Sung, B.; Lee, Y. Effects of high occupational physical activity, aging, and exercise on heart rate variability among male workers. Ann. Occup. Environ. Med. 2015, 27, 22. [CrossRef]

28. Barutcu, I.; Esen, A.M.; Kaya, D.; Turkmen, M.; Karakaya, O.; Melek, M.; Esen, O.B.; Basaran, Y. Cigarette Smoking and Heart Rate Variability: Dynamic Influence of Parasympathetic and Sympathetic Maneuvers. Ann. Noninvasive Electrocardiol. 2005, 10, 324-329. [CrossRef]

29. Murgia, F.; Melotti, R.; Foco, L.; Gögele, M.; Meraviglia, V.; Motta, B.; Steger, A.; Toifl, M.; Sinnecker, D.; Müller, A.; et al. Effects of smoking status, history and intensity on heart rate variability in the general population: The CHRIS study. PLoS ONE 2019, 14, e0215053. [CrossRef]

30. Harte, C.B.; Meston, C.M. Effects of Smoking Cessation on Heart Rate Variability among Long-Term Male Smokers. Int. J. Behav. Med. 2013, 21, 302-309. [CrossRef] [PubMed]

31. Burch, J.B.; Alexander, M.; Balte, P.; Sofge, J.; Winstead, J.; Kothandaraman, V.; Ginsberg, J.P. Shift Work and Heart Rate Variability Coherence: Pilot Study among Nurses. Appl. Psychophysiol. Biofeedback 2019, 44, 21-30. [CrossRef]

32. Hulsegge, G.; Gupta, N.; Proper, K.I.; van Lobenstein, N.; Ijzelenberg, W.; Hallman, D.M.; Holtermann, A.; van der Beek, A.J. Shift work is associated with reduced heart rate variability among men but not women. Int. J. Cardiol. 2018, 258, 109-114. [CrossRef]

33. Jensen, M.A.; Garde, A.H.; Kristiansen, J.; Nabe-Nielsen, K.; Hansen, Å.M. The effect of the number of consecutive night shifts on diurnal rhythms in cortisol, melatonin and heart rate variability (HRV): A systematic review of field studies. Int. Arch. Occup. Environ. Health 2016, 89, 531-545. [CrossRef] [PubMed]

34. Malmberg, B.; Persson, R.; Flisberg, P.; Ørbaek, P. Heart rate variability changes in physicians working on night call. Int. Arch. Occup. Environ. Health 2010, 84, 293-301. [CrossRef]

35. Hermans, B.; Verheyden, B.; Beckers, F.; Aubert, A.; Puers, R. A portable multi-sensor datalogger for heart rate variability (HRV) study during skydiver's free fall. In Proceedings of the the 13th International Conference on Solid-State Sensors, Actuators and Microsystems, 2005. Digest of Technical Papers. TRANSDUCERS '05, Seoul, Korea, 5-9 June 2005.

36. Cavalade, M.; Papadopoulou, V.; Theunissen, S.; Balestra, C. Heart rate variability and critical flicker fusion frequency changes during and after parachute jump-ing in experienced skydivers. Eur. J. Appl. Physiol. 2015, 115, 1533-1545. [CrossRef]

37. Mazurek, K.; Koprowska, N.; Gajewski, J.; Skibniewski, F.; Zmijewski, P.; Różanowski, K. Parachuting training improves autonomic control of the heart in novice parachute jumpers. Biocybern. Biomed. Eng. 2018, 38, 181-189. [CrossRef]

38. Pawlosky, N. Cardiovascular risk: Are all NSAIDs alike? Can. Pharm. J. 2013, 146, 80-83. [CrossRef] [PubMed]

39. Koenig, J.; Jarczok, M.N.; Hillecke, T.K.; Thayer, J.F. Analgesic Self-Medication and Heart Rate Variability-A Preliminary Investigation. American Psychosomatic Society (APS). In Proceedings of the 72nd Annual Scientific Meeting, Stretching the Boundaries: From Mechanisms of Disease to Models of Health, San Francisco, CA, USA, 13 March 2014.

40. Bavry, A.A.; Khaliq, A.; Gong, Y.; Handberg, E.M.; Cooper-DeHoff, R.M.; Pepine, C.J. Harmful Effects of NSAIDs among Patients with Hypertension and Coronary Artery Disease. Am. J. Med. 2011, 124, 614-620. [CrossRef] [PubMed]

41. Tegegne, B.S.; Man, T.; Van Roon, A.M.; Riese, H.; Snieder, H. Determinants of heart rate variability in the general population: The Lifelines Cohort Study. Hear. Rhythm. 2018, 15, 1552-1558. [CrossRef] [PubMed]

42. Rodrigues, T.S.; Quarto, L.J.G. Body Mass Index May Influence Heart Rate Variability. Arq. Bras. Cardiol. 2018, 111, 640-642. [CrossRef] [PubMed]

43. Jouanin, J.-C.; Dussault, C.; Pérès, M.; Satabin, P.; Piérard, C.; Guézennec, C.Y. Analysis of Heart Rate Variability after a Ranger Training Course. Mil. Med. 2004, 169, 583-587. [CrossRef] [PubMed]

44. Minassian, A.; Geyer, M.A.; Baker, D.G.; Nievergelt, C.M.; O'Connor, D.T.; Risbrough, V.B. Heart Rate Variability Characteristics in a Large Group of Active-Duty Marines and Relationship to Posttraumatic Stress. Psychosom. Med. 2014, 76, $292-301$. [CrossRef] [PubMed]

45. Schneider, C.; Wiewelhove, T.; Raeder, C.; Flatt, A.A.; Hoos, O.; Hottenrott, L.; Schumbera, O.; Kellmann, M.; Meyer, T.; Pfeiffer, M.; et al. Heart Rate Variability Monitoring During Strength and High-Intensity Interval Training Overload Microcycles. Front. Physiol. 2019, 10, 582. [CrossRef]

46. Phoemsapthawee, J.; Prasertsri, P.; Leelayuwat, N. Heart rate variability responses to a combined exercise training program: Correlation with adiposity and cardiorespiratory fitness changes in obese young men. J. Exerc. Rehabil. 2019, 15, 114-122. [CrossRef]

47. Andrew, M.E.; Violanti, J.M.; Gu, J.K.; Fekedulegn, D.; Li, S.; Hartley, T.A.; Charles, L.E.; Mnatsakanova, A.; Miller, D.B.; Burchfiel, C.M. Police work stressors and cardiac vagal control. Am. J. Hum. Biol. 2017, 29, e22996. [CrossRef] [PubMed]

48. Borchini, R.; Ferrario, M.M.; Bertù, L.; Veronesi, G.; Bonzini, M.; Dorso, M.; Cesana, G. Prolonged job strain reduces time-domain heart rate variability on both working and resting days among cardiovascular-susceptible nurses. Int. J. Occup. Med. Environ. Health 2014, 28, 1-10. [CrossRef] [PubMed] 
49. Hourani, L.L.; Davila, M.I.; Morgan, J.; Meleth, S.; Ramirez, D.; Lewis, G.; Kizakevich, P.N.; Eckhoff, R.; Morgan, T.; Strange, L.; et al. Mental health, stress, and resilience correlates of heart rate variability among military reservists, guardsmen, and first responders. Physiol. Behav. 2020, 214, 112734. [CrossRef] [PubMed]

50. Low, A.; McCraty, R. Emerging dynamics of workplace stress of employees in a large organization in Hong Kong. Public Adm. Policy 2018, 21, 134-151. [CrossRef]

51. Nikolova, R.; Aleksiev, L.; Vukov, M. Psychophysiological assessment of stress and screening of health risk in peace-keeping operations. Mil. Med. 2007, 172, 44-48. [CrossRef] [PubMed]

52. Plews, D.J.; Laursen, P.B.; Stanley, J.; Kilding, A.E.; Buchheit, M. Training Adaptation and Heart Rate Variability in Elite Endurance Athletes: Opening the Door to Effective Monitoring. Sports Med. 2013, 43, 773-781. [CrossRef]

53. Tomes, C.; Schram, B.; Orr, R. Relationships between Heart Rate Variability, Occupational Performance, and Fitness for Tactical Personnel: A Systematic Review. Front. Public Health 2020, 8. [CrossRef]

54. Fernández-Donet, R.; Marco-Ahulló, A.; Bermejo, J.L.; Monfort-Torres, G. Epidemiología y principales causas de lesión de militares pertenecientes al ejército de tierra. J. Sport Health Res. 2021, 13, 93-102.

55. Baldassarre, A.; Mucci, N.; Padovan, M.; Pellitteri, A.; Viscera, S.; Lecca, L.I.; Galea, R.P.; Arcangeli, G. The Role of Electrocardiography in Occupational Medicine, from Einthoven's Invention to the Digital Era of Wearable Devices. Int. J. Environ. Res. Public Health 2020, 17, 4975. [CrossRef] [PubMed]

56. Baldassarre, A.; Mucci, N.; Lecca, L.I.; Tomasini, E.; Parcias-Do-Rosario, M.J.; Pereira, C.T.; Arcangeli, G.; Oliveira, P.A.B. Biosensors in Occupational Safety and Health Management: A Narrative Review. Int. J. Environ. Res. Public Health 2020, 17, 2461. [CrossRef]

57. Di Fabio, A.; Kenny, M.E. From Decent Work to Decent Lives: Positive Self and Relational Management (PS\&RM) in the Twenty-First Century. Front. Psychol. 2016, 7, 361. [CrossRef] [PubMed]

58. Marhavilas, P.; Koulouriotis, D.; Nikolaou, L.; Tsotoulidou, S. International Occupational Health and Safety Management-Systems Standards as a Frame for the Sustainability: Mapping the Territory. Sustainability 2018, 10, 3663. [CrossRef] 